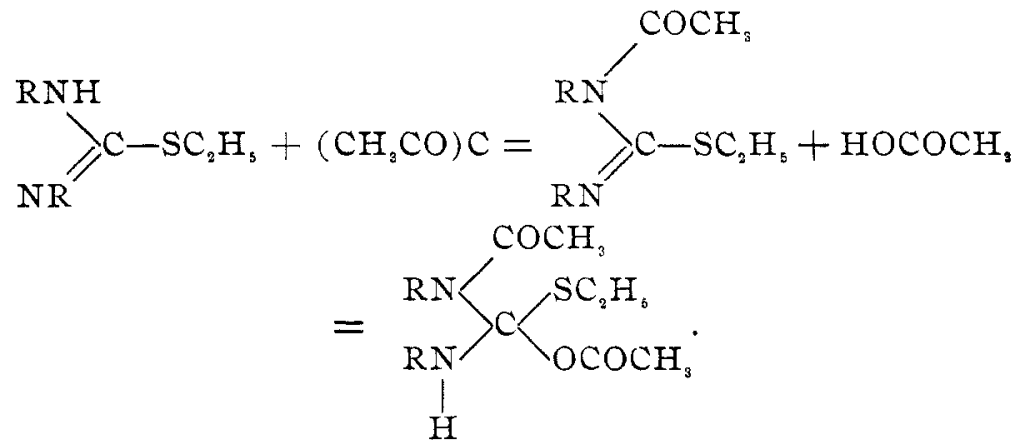

Action of Benzoyl Chloride. - Ten grams of ethyl isodiphenyl thiourea and 3 grams of benzoyl chloride were dissolved in benzene and allowed to stand for a week. The crystals that separated weighed 5.7 grams and consisted of the pure hydrochloride of the ethyl ether (m. p. $178^{\circ}$ ). After distilling off the benzene, an oil was left, insoluble in ammonia or dilute hydrochloric acid, the benzoyl ethyl thiodiphenyl urea. It was not obtained pure enough for analysis. An effort was made to distil the oil but decomposition ensued, with the formation of much tar, some phenyl isocyanate, and carbodiphenyl imide. Another portion heated in a sealed tube with hydrochloric acid, at $140^{\circ}$, gave ethyl chloride, carbon dioxide, mercaptan, aniline, and benzoic acid, so that while the body was not analyzed, its identity is fairly well established.

NORTHWESTERN UNIVERSITY CHEMICAL LABORATORIES, 242I DEARBORN ST., CHICAGO, March, I 900 .

\title{
THE TECHNICAL ESTIMATION OF ZINC.
}

By Albert H. Low.

Received February 26, 1900 .

I $\mathrm{N}$ a report read June I I, I892, before the Colorado Scientific Society, the method devised by the writer for the technical estimation of zinc in ores, etc., was approved as the best that had come to the attention of the committee. Although it had its weak points, some of which were recognized at the time, it was nevertheless well adapted for rapid and accurate work on the majority of Colorado ores and, in fact, no better method has since been offered. 
Applications for a description of the method are very frequent, and in view of the fact that daily use in the laboratory for several years has naturally resulted in some changes from the original plan, it may not be out of place to again publish the scheme in its latest form. It is, of course, apparent that the method as given is not of universal application. Sometimes a fusion may be necessary to effect complete decomposition, or perhaps a preliminary treatment with hydrochloric acid may be required. (All hydrochloric acid must be expelled before beginning the regular treatment.) The operator is expected to recognize such cases and apply the remedy. He is cautioned, however, to be very careful about modifying the method except from actual necessity. Not that improvements are not possible, but it has been the writer's experience that most of the failures result either from inattention to details or the introduction of supposed improvements by the operator.

\section{DESCRIPTION OF THE METHOD.}

Standard Ferrocyanide Solution.-Digsolve 22 grams of potassium ferrocyanide crystals in water and dilute to I liter. Standardize as follows: Weigh carefully about roo mg. of pure zinc and dissolve in $6 \mathrm{cc}$. of strong hydrochloric acid, using a $400 \mathrm{cc}$. beaker. Then add about io grams of ammonium chloride and $200 \mathrm{cc}$. of boiling water. Titrate with the ferrocyanide solution until a drop, when tested on a porcelain plate with a drop of a strong solution of uranium nitrate, shows a brown tinge. About $20 \mathrm{cc}$. of ferrocyanide will be required, and accordingly nearly this amount may be run in rapidly before making a test, and then the titration finished carefully by testing after each additional drop. Instead of using a single drop of the zinc solution for the test, the reaction is much sharper if several drops are placed in a depression of the plate and tested with a single drop of a strong uranium solution. As this is near the end of the titration the amount of zinc lost thereby is insignificant. As soon as a brown tinge is obtained, note the reading of the burette and then wait a minute or two and observe if one or more of the preceding tests do not also develop a tinge. The end-point is usually passed by a test or two and the burette reading must be accordingly corrected. A further correction must be made for 
the amount of ferrocyanide required to produce a tinge under the same conditions when no zinc is present. This is only I or 2 drops. One cc. of the standard solution will equal about 0.005 gram of zinc, or about I per cent. when 0.5 gram of ore is taken for assay.

Assay of Ores.-To $0.5 \mathrm{gram}$ of ore in a $250 \mathrm{cc}$. pear-shaped flask, add about 2 grams of potassium nitrate and $5 \mathrm{cc}$. of strong nitric acid. Heat until the acid is about half gone and then add Io $\mathrm{cc}$. of a cold saturated solution of potassium chlorate in strong nitric acid and boil to complete dryness. It is usually necessary to manipulate the flask in a holder over a naked flame to avoid loss by bumping. The boiling may be conducted rapidly, and towards the end it is best to heat the entire flask so as to expel every trace of liquid. The potassium nitrate serves simply as a diluent of the dry residue and insures the completeness of the subsequent extraction of the zinc. Cool sufficiently and add 30 cc. of a prepared ammoniacal solution and heat to boiling. This solution is made by dissolving 200 grams of ammonium chloride in a mixture of $500 \mathrm{cc}$. of strong ammonia water and $350 \mathrm{cc}$. of water. Boil the contents of the flask very gently for about two minutes and then filter through a $9 \mathrm{~cm}$. filter and wash with a hot solution of ammonium chloride containing about roo grams of the salt and $50 \mathrm{cc}$. of strong ammonia water to the liter. Collect the filtrate in a $400 \mathrm{cc}$. beaker. The insoluble residue should be completely disintegrated and any ferric hydroxide present should appear of a fine sandy nature. Place a bit of litmus paper in the filtrate (not necessary if much copper is present), and neutralize carefully with hydrochloric acid, finally adding 6 cc. of the strong acid in excess. Dilute to about $150 \mathrm{cc}$. and add $50 \mathrm{cc}$. of a cold saturated solution of hydrogen sulphide. Heat nearly to boiling and the solution is ready for titration. If more convenient, or apparently advisable, pass a current of hydrogen sulphide gas through the hot solution diluted to $200 \mathrm{cc}$. Copper and cadmium, which are interfering metals, are thus precipitated. Unless in large amount they need not be filtered off. Practically no zinc is precipitated with the copper under these conditions and the discoloration of the liquid by even Io per cent. of copper does not badly mask the uranium test. Titrate the 
hot solution as follows : Pour off about one-third and set it aside in a beaker. Titrate the remainder, more or less rapidly, according as much or little zinc is indicated, until the end-point is passed, using the uranium indicator as in the standardization. Now add the greater part of the reserved portion and continue the titration with more caution until the end-point is again passed. Finally add the last of the reserved portion and finish the titration carefully, ordinarily two drops at a time. Make corrections of the final reading of the burette precisely as in the standardization. The true end-point is always slightly passed, and, after waiting a minute, it is usually sufficient to deduct for as many drops as show a brown tinge and one test additional.

Notes.-When precipitating with hydrogen sulphide it is a matter of considerable importance to have the solution of a definite degree of acidity, Cadmium and copper are to be precipitated, while it is better to retain lead in solution and not unnecessarily blacken the liquid with its sulphide. If there is enough acid to prevent the precipitation of its sulphide the lead will not interfere in the titration. On the other hand too much acid will prevent the precipitation of the cadmium. It will not come down from a boiling hot solution containing 5 per cent. of strong hydrochloric acid. It is readily precipitated from a 3 per cent. solution while lead is not, if the liquid be nearly boiling. It is therefore recommended to have an excess of $6 \mathrm{cc}$. of strong hydrochloric acid in the final bulk of $200 \mathrm{cc}$. of solution.

Arsenic, when present in large a mount, sometimes makes trouble by retaining iron in the ammoniacal solution. No attention need be paid to arsenic unless its presence in excess is thus indicated. In such a case begin anew and give the ore a preliminary treatment as follows:

To 0.5 gram of ore in the flask add Io cc. of strong hydrochloric acid and I cc. of bromine. Warm very gently for several minutes to decompose the ore without loss of bromine and then boil rapidly to complete dryness. The arsenic will thus be sufficiently expelled. Now add the potassium nitrate and nitric acid and proceed in the usual manner.

In the case of ores that are free from cadmium, or where cadmium may be neglected, the copper may be readily precipitated without the use of hydrogen sulphide as follows: After neutral- 
izing the ammoniacal filtrate from the insoluble residue, acidify with an excess of Io cc. of hydrochloric acid and add about 30 grams of granulated test lead. Heat nearly to boiling and stir the lead about until all the copper is precipitated. Now dilute to $200 \mathrm{cc}$. and titrate as described, without removing the lead and precipitated copper.

Denver, Colorado, Februaty $20,1900$.

[CONTRIBUTIONS FROM THE HAVEMEYER LABORATORIES OF COLUMBI 1 UNIVERSITY, NO. 2I.]

\title{
A NEW BRIDGE ARRANGEMENT FOR THE DETERMI- NATION OF ELECTROMOTIVE FORCE BY AID OF THE LIPPMANN ELECTROMETER.
}

\author{
By J. LivingstoN R. MORGaN.
}

Received Fabruary 3, Ig00.

TH

$\mathrm{HE}$ two-bridge arrangements given by Ostwald ${ }^{1}$ for the measurement of electromotive force by the aid of the Lippmann electrometer are the only two at present in use for primary cells. When an accumulator is used, it is only necessary to connect it through a meter of manganine wire and to compensate the cell to be measured by a fraction of the source taken off from the wire by a sliding contact." If a primary cell were used in this way the results would not be accurate, owing to the decrease in the electromotive force of the cell due to the small resistance of the wire (50 ohms at most). Of the two methods in which primary cells may be used as a source, we may say that each is good for its purpose but that neither is of general utility. The method using the sliding contact as already described for an accumulator necessitates the use of a spool at one end of the bridge wire, which contains thirteen times the resistance of the bridge wire. In this way the cell is connected through 700 ohms ( $4 \times 50$ ) so that its electromotive force remains constant during the operation. By this, however, the drop in potential at the ends of the wire, with a Leclanché cell (I.4 volts), is only 0. I volt, so that nothing larger than that can be measured, unless some elaborate device is provided by which another known electromotive force may be placed against the one to be

1 Hand- und Filfsuch zur Ausfihrung physico-chemischer Messunger, 252-253.

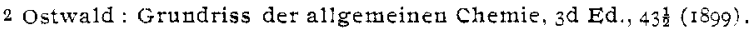

